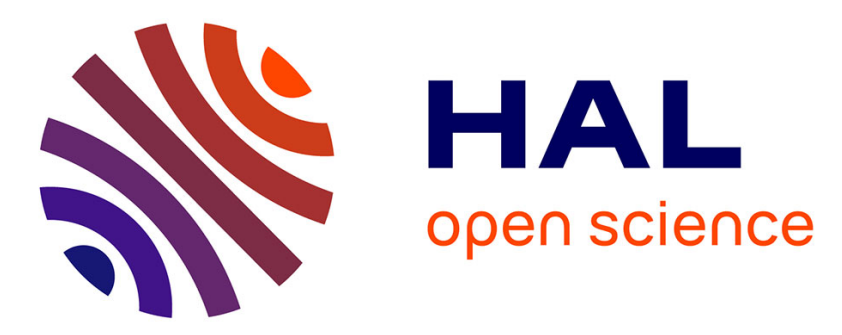

\title{
Switching Between Expectation Processes in the Foreign Exchange Market: A Probabilistic Approach Using Survey Data
}

\author{
Georges Prat, Remzi Uctum
}

\section{- To cite this version:}

Georges Prat, Remzi Uctum. Switching Between Expectation Processes in the Foreign Exchange Market: A Probabilistic Approach Using Survey Data. Review of International Economics, 2007, 15 (4), pp.700-719. halshs-00081586

\section{HAL Id: halshs-00081586 \\ https://shs.hal.science/halshs-00081586}

Submitted on 23 Jun 2006

HAL is a multi-disciplinary open access archive for the deposit and dissemination of scientific research documents, whether they are published or not. The documents may come from teaching and research institutions in France or abroad, or from public or private research centers.
L'archive ouverte pluridisciplinaire HAL, est destinée au dépôt et à la diffusion de documents scientifiques de niveau recherche, publiés ou non, émanant des établissements d'enseignement et de recherche français ou étrangers, des laboratoires publics ou privés. 
REVIEW OF INTERNATIONAL ECONOMICS

MS\#5007, Acceptance date: December 28, 2005

Switching Between Expectation Processes in the Foreign Exchange Market:

A Probabilistic Approach Using Survey Data*

Georges Prat

Remzi Uctum

RRH: SWITCHING BETWEEN EXPECTATION PROCESSES

LRH: Georges Prat and Remzi Uctum

\begin{abstract}
This paper relaxes a fundamental hypothesis commonly accepted in the expectation formation literature: expectations are, unchangingly, either rational or generated by one of the three simple extrapolative, regressive or adaptive processes. Using expectations survey data provided by Consensus Forecasts on six European exchange rates against US Dollar, we find that the rational expectation hypothesis is rejected at the aggregate level. By implementing a switching regression methodology with stochastic choice of regime, we show that the expectation generating process is given at any time by some combination of the three simple processes. An interpretation of this framework in terms of economically rational expectations is suggested.
\end{abstract}

* Prat and Uctum: Centre National de la Recherche Scientifique (CNRS) and University ParisX Nanterre (EconomiX), Bat. G, 200 avenue de la République 92001 Nanterre, France. Tel : +3314097 5968 and +33 1409778 48, Fax: +33 14097 77 84, E-mail : prat@u-paris10.fr and uctum@u-paris10.fr. We wish to thank Merih Uctum for useful discussions and two anonymous referees whose comments improved the paper considerably.

JEL Classification Numbers: F31, D84, E44, C51

Abbreviations: CF, REH, EMS, UIRP, PPP, CPI, PPI, ECM, STAR, TAR, SSR, SUR, FIML

Number of Figures: $1 \quad$ Number of Tables: 6

Date: March 20, 2006

Address of Contact Author: Remzi Uctum, EconomiX (UMR 7166), Université Paris-X Nanterre, Bat. G, 200 avenue de la République 92001 Nanterre, France. Tel : +33 1409778 48, Fax: +331 409777 84, E-mail: uctum@u-paris10.fr. 


\section{Introduction}

Because asset price expectations govern actual market prices, knowledge of the process which generates asset price expectations is fundamental to understanding how these market prices are determined. For example, many models of exchange rate determination may be expressed as a linear combination of the expected change in exchange rate and its fundamentals, ${ }^{1}$ making the volatility of the spot rate clearly dependent of how expectations are generated. The aim of this paper is precisely to enhance our understanding of this expectations-generating process.

The literature on expectations in the foreign exchange market using survey data has found evidence against the unbiasedness of expectations and against orthogonality of forecast errors with respect to some exogenous variables (MacDonald, 1991). These results lead to the conclusion that the Rational Expectations Hypothesis (REH) is not relevant in the sense that expectations are not conditional on the whole set of available information. On the other hand, the literature has also shown that the three standard processes - extrapolative, regressive and adaptive - are insufficient by themselves to explain expectation formation (Allen and Taylor, 1990; Frankel and Froot, 1987). Moreover, any attempt to expand these processes by inclusion of macroeconomic variables - thus by considering a fundamental behavior - does not seem to do better. These results hold regardless the source of the survey data, the type of the data used (consensus versus microdata), and the horizon of expectations. Overviews on these issues are provided by Takagi (1991) and MacDonald (2000).

This failure in modeling how expectations are formed may be the result of two hypotheses generally admitted in the literature: (i) the same process prevails at any time of the sample period, and (ii) this is either the extrapolative, or the regressive, or the adaptive process, or any process involving macroeconomic fundamentals (that we hereafter call the fundamental process) or the one underlying the REH. In fact, a few studies drop assumption (ii). For example, Frankel and Froot $(1986,1987,1990)$ introduce the idea of mixed processes such as the extrapolative-regressive model (representing the chartists' and fundamentalists' behavior) or the adaptive-extrapolative model. Employing different exchange rate survey data, they do not however report any significant result concerning the relevance of these mixed models. By contrast, using Consensus Forecasts survey data on various exchange rate expectations, Prat and Uctum (2000) show the relevance at the aggregate level of an extrapolative-regressive-adaptive mixed process, while Bénassy, Larribeau and MacDonald (2003) validate a similar mixed model on a disaggregated level.

The studies examining in the light of survey data the question of whether the forecast function changes over time (assumption (i)) are surprisingly scarce. Frankel and Froot (1987) have only introduced the idea but did not model it further. Using survey data of the yen/dollar exchange rate, Ito (1994) has tested over different sub-periods a bandwagon model for the one-month ahead expectations and a mean-reversion model for three to six month horizons, finding some stability in these models. However, this analysis is based on an arbitrarily partitioned sample, and a more appropriate method would consist in implementing a switching-regime model with unknown breakpoints. The only studies on expectation formation using a switching regime methodology have examined the time-varying pattern of expectation processes implicitly, through a spot exchange rate modeling framework. Among the related studies, Vigfusson (1997) estimates a Markov switching regime model and finds that chartists' activities explain the exchange rate dynamics in periods of low volatility whereas fundamentalists' activities represent it in periods of high volatility. Bessec and Robineau (2003) expand the previous model by showing that there exists some coexistence of the two groups in each regime. Nevertheless, these studies do not deal explicitly with the 
question of how expectations are formed. Furthermore, they have only been concerned by the chartist-fundamentalist framework and have never included other behaviour such as the adaptive one.

This paper explores the joint hypothesis that (i) the anticipation-generating process changes over time and (ii) expectations are generated by a mixed process. In Section 2 we expand the economically rational expectations theory (Feige and Pearce, 1976) in order to provide an appropriate theoretical framework explaining why expectation processes may be mixed and why they may change over time. Section 3 shows the irrelevance of the REH, identifies the alternative expectation processes and presents a switching-regime model allowing these processes to change over time. Section 4 presents the empirical results of this model using Consensus Forecasts survey data of European currencies relative to the US dollar. Section 5 concludes.

\section{Theoretical Aspects of the Expectation Behavior}

When information is costless and the "true" data generating process of the exchange rate is known, the forecast model of exchange rate is optimal in the sense that the forecast error variance is minimum. This implies that expectations are rational. For instance, if the change in the exchange rate is represented as a sequence of stochastic observed shocks, the adaptive process is optimal (Muth, 1960). If, alternatively, the change in the exchange rate has an autoregressive representation, the optimal expectation process is of the extrapolative form (Baillie and MacMahon, 1992). If it exhibits a mean-reversion dynamics, the optimal expectation process is of the regressive form (Holden, Peel and Thomson, 1995). Finally, if it is represented by lagged macroeconomic factors, the expected change in exchange rate is given by actual and lagged macroeconomic variables. Of course, one can consider a complex generating process defined as some combination of the preceding simple processes, and it can be shown that the optimal expectation process in this case is a mixed process. Nevertheless, empirical studies based on survey data reject the null of unbiasedness (MacDonald, 2000) and also the one of homogeneity (Bénassy-Quéré, Larribeau and MacDonald, 2003; Ito, 1990; MacDonald and Marsh, 1996) of exchange rate expectations. These results, which clearly contradict the REH, may be interpreted as being due to an unachieved learning process (Frankel and Froot, 1987), or to a 'peso effect' (Kaminsky, 1993) or to voluntarily unused information due to information costs (Feige and Pearce, 1976). However, no empirical study using survey data has detected any evidence of improvement over time in the accuracy of exchange rate expectations, suggesting that no significant learning effects can be found at the aggregate level. On the other hand, a peso effect may generate expectation bias but it implies homogeneity. ${ }^{2}$ Therefore, this effect seems not to be relevant to explain the empirical results mentioned above. In fact, bias and heterogeneity may both be explained by the existence of informational costs. This is in line with the economically rational expectation framework introduced by Feige and Pearce (1976), where the expectation process chosen by the agents at any time results from a cost-and-advantage analysis of information.

Let $I_{i t}^{j}$ be a measurable amount of information of type $i(\mathrm{i}=1,2, \ldots, \mathrm{n})^{3}$ that agent $j$ may use to forecast at time $\mathrm{t}$ and $c_{i t}^{j}$ the price of collecting and processing a unit of this information supported by this agent. Assuming constant returns to scale, $c_{i t}^{j}$ is a marginal cost. Let $f$ be a twice continuously differentiable function relating the information inputs $I_{i t}^{j}$ to the agent's expected quadratic forecast error. We assume:

$$
E_{t}\left(\tilde{s}_{t, \tau}^{j}-s_{t+\tau}\right)^{2}=f\left(I_{1 t}^{j}, \ldots, I_{i t}^{j}, \ldots I_{n t}^{j}\right) \quad f_{i}<0, \quad f_{i i}>0 \quad i=1, \ldots n
$$


where $s_{t}$ is the logarithm of the spot exchange rate and $\widetilde{s}_{t, \tau}^{j}$ is the logarithm of the expected exchange rate at time $t$ for the horizon $\tau$ by agent $j .{ }^{4}$

The sign of the first derivative of $f$ means that the more the agent collects information the more (s)he expects to reduce the squared forecast error through some underlying expectation process. The sign of the second derivative says that the marginal efficiency of information decreases as $I_{i t}^{j}$ increases. To determine the optimal amount of each type of information, the forecaster minimizes at any time the following total cost:

$$
C_{t}^{j}=\pi_{t}^{j} f\left(I_{1 t}^{j}, I_{2 t}^{j}, \ldots I_{n t}^{j}\right)+\sum_{i=1}^{n} c_{i t}^{j} I_{i t}^{j},
$$

where $\pi_{t}^{j}>0$ is the agent's aversion of misestimating future rates and $\pi_{t}^{j} f$ represents his/her loss function. A given forecast error is all the more costly than the aversion is high. At the equilibrium, equation (2) implies:

$$
c_{i t}^{j}=-\pi_{t}^{j} d f / d I_{i t}^{j}, \quad \mathrm{i}=1,2, \ldots, \mathrm{n}
$$

This equilibrium condition leads to $I_{i t}^{j^{*}}$, the optimal amount of information of type $i$ used by agent $j$ at time $t$. Equation (3) says that this amount of information is chosen in such a way that the marginal gain - i.e., the marginal decrease in the loss function - due to the decrease in the forecast error equals the unit cost. Note that when the cost/aversion ratio $c_{i t}^{j} / \pi_{t}^{j}$ tends to zero $\left(c_{i t}^{j} \rightarrow 0\right.$ or $\pi_{t}^{j} \rightarrow \infty$ ), then $I_{i t}^{j^{*}}$ converges to all available information of type $i$. When information of all types is costless, then the expected quadratic forecast error, which is equivalent to the forecast error variance, cannot be reduced further. In this case the economic rationality converges to the Muthian rationality (Muth, 1961). Conversely, for a given $\pi_{t}^{j}$, the forecaster ignores all information (and becomes a noise-trader) when the cost exceeds the limit value corresponding to his/her maximum marginal gain. Generally speaking, the optimal amount of information may differ from an agent to another because of the discrepancies in the individual cost/aversion ratios $c_{i t}^{j} / \pi_{t}^{j}$. This generates heterogeneity in expectation behavior and justifies a representation of expectations in terms of a mixed process at the aggregate level. To illustrate this, consider the two following polar situations giving rise to a mixed process: (i) the market is made by different groups of agents, each of them using a simple process (group-heterogeneity effect); (ii) all forecasters use the same mixed process, which is a combination of simple processes (individual weighting effect). A well-known example of a mixed model of type (i) is the chartist and fundamentalist model by Frankel and Froot (1986). In fact, because groups in case (i) may also be made by forecasters using mixed processes, the two effects may operate simultaneously and this reinforces the relevance of an overall mixed model. Oberlechner (2001) found, on four European foreign exchange markets, that most traders use both fundamental and chartist approaches and that distinct groups of traders can be identified according to different forecasting methods and horizons. These findings support the effects (i) and (ii) described above.

Equation (3) helps to understand why processes may change over time. The ratio $c_{i t}^{j} / \pi_{t}^{j}$ is influenced by, say, the degree of the volatility of the economy. On the one hand, the degree of aversion $\pi_{t}^{j}$ may depend on this volatility ${ }^{5}$ and on the other hand, the increasing instability may require more complex statistical tools and thus push up the cost of processing 
information $c_{i t}^{j}$. However, the sign of the total influence of volatility on the cost/aversion ratio remains undetermined.

To sum up, the change over time and across forecasters of the cost/aversion ratio can explain both the change in the expectation process from one period to another and the mixed pattern of the process at the aggregate level. However, it should be emphasized that this ratio is not an observable magnitude and therefore its relation with expectation formation is not testable. The theory proves nevertheless useful in that it provides strong insight to interpreting why expectations can be mixed and time-varying. What is testable is that expectations are not generated by a permanent standard process, and this is the issue we will examine in the next section by implementing a probabilistic switching-regime model where each regime is defined by a specific combination of simple processes.

\section{The Empirical Approach}

\section{The Data}

Since November 1989, «Consensus Forecasts » of London (CF) asks at the beginning of each month to 180 or so economy and capital market specialists in about 30 countries to estimate future values of a large number of economic variables for 3-month and 12-month time-horizons (expanded to 24-month horizon since December 1994 and to 1-month horizon since January 1996). Among these variables are the spot exchange rates. Towards the end of each month, CF sends by fax to each of the experts (scattered throughout the world) who have agreed to participate in the survey, a questionnaire in which they are asked to give their opinion on the future numerical values of the spot rates. The consensus is the arithmetic average of the individual responses and is published in the monthly CF newsletter. The consensus time series used in this paper cover the period 1990:06 - 1997:06 (85 months) and are related to European currencies against the US dollar (USD): the French franc (FRF), the German mark (DEM), the British pound (GBP), the Danish krone (DKK), the Irish punt (IEP) and the Italian lira (ITL). ${ }^{6}$ The starting date is chosen so that data are available for the six currencies. The end of the period is chosen so as to exclude a turbulence period of six months between the horizon of the last one-year ahead expectation provided by the experts and the beginning of the Euro era (January 1, 1999).

The CF requires a very specific day for the answers at the beginning of the month. ${ }^{7}$ As a rule, this day is the same for all respondents. Given that the questions concern the expected level of the spot rate, the expected change in exchange rate can only be calculated using the value of the spot rate which is assumed to be known by all the individuals at the day of the answer (reference rate). It is thus clear that any error in the choice of the reference rate date implies a mistake in the measurement of the expected change. However, the spot rate values considered in this paper being dated from the day required by CF for the answers, the concentration of the answers on the same day implies that we can retain the same reference spot rate for all respondents.

Respondents are commercial or investment banks, industrial firms and forecast companies, whose forecasts influence many other market participants' decisions. These experts are identified with a confidential code, which only reveals their country. They are asked to respond only when they are concerned by the foreign exchange market. Depending on currencies, between one and two thirds of the 180 experts of CF answer the questions concerning future values of the spot rates. The abstention ratio suggests that respondents are informed agents and are professionally involved in the requested horizons. Since the individual answers are confidential (only the consensus is disclosed to the public with a time lag) and since each individual is negligible within the consensus, it is difficult to claim that, for reasons which are inherent to speculative games, individuals might not reveal their 
" true » opinion. Note that these considerations only suggest that the responses are not distorted but they do not imply that the consensus represents an unbiased proxy of the market expectations. However, regarding the existence of the 3-month forward market, one can argue that there is an incentive for experts to compare their expected rate to the forward rate, this implying that their expectations should capture a market component. If we were to interpret the consensus expectation as a market expectation, we would only need to suppose that the latter equals the former plus an intercept (representing the systematic component of the measurement error) and a white noise (standing for the random component of the measurement error). ${ }^{8}$ However, our analysis focuses on how the experts solicited by CF form their expectations, and therefore we do not need to go through this interpretation.

Another important issue is the real meaning of the reported rates in the survey. Especially, if experts report a risk-adjusted expectation (i.e., the future value of the product of the kernel price and exchange rate) instead of their actual expectation, that is, if they do not respond what they are asked to, then any attempt to model the consensus according to a pure expectation process would be of course irrelevant. However, two arguments allow us to interpret the provided rate as an expectation, as CF do. First, the existence of a 3-month ahead forward exchange market induces agents to distinguish their expectation from the forward rate, and then to separate the expected exchange rate from the risk premium. Second, because the exchange rate is defined as the relative price of a European currency and the US dollar, a good state of the nature for a European expert will be viewed as a bad state for an American expert, and these opposite views may be offset through the consensus of experts.

Finally, we assume that the opinion variable of agent $j$ is his expected return $\tilde{s}_{t, \tau}^{j}-s_{t}$, where $\tau=3,12$. Since agents are asked by CF to give their opinions about the level (and not the log-level) of the future spot rate, they express their responses as $\tilde{S}_{t, \tau}^{j}=S_{t} \exp \left(\tilde{s}_{t, \tau}^{j}-s_{t}\right)$, where $\tilde{S}_{t, \tau}^{j}$ and $S_{t}$ denote the expected exchange rate and the spot rate, respectively. Therefore, at the aggregate level, the expected exchange rate should be the geometric average of $\tilde{S}_{t, \tau}^{j}$. However, the consensus value published by CF is an arithmetic average of expected exchange rates. Hence, constructing the aggregate expected return using the latter measure instead of the former generates a systematic bias. It can be shown that the wider the dispersion of individual expectations the larger is the bias. Because in our data this dispersion is rather low and stable over time for the two horizons, ${ }^{9}$ this bias will be supposed to be constant. We will therefore introduce in each process an intercept to capture this bias, and write the dependent variable as $\tilde{s}_{t, \tau}-s_{t}$, where $\tilde{s}_{t, \tau}$ is the logarithm of the arithmetic average of $\tilde{S}_{t, \tau}^{j}$ provided by CF.

\section{Identifying the Regimes of the Switching-Regression Model}

As shown in Section 2, the expectation process chosen by agents may change at any time because of time varying costs and marginal gains associated with information. This suggests that a switching regime model is appropriate to modeling expected change in exchange rate, where each regime corresponds to an expectation process. This section aims to identify the relevant regimes.

A first important issue is to examine whether or not the consensus provides indication of rationality. We thus implemented the unbiasedness test for each currency over the sample period by regressing the three month ahead expected change $\tilde{s}_{t, 3}-s_{t}$ on the ex-post rate of change $s_{t+3}-s_{t}$. We also included a MA(2) process in order to correct the possible 
overlapping data bias which may arise from our monthly data of 3-month ahead expectations (MacDonald, 2000, p.179):

$$
\begin{aligned}
& \tilde{s}_{t, 3}-s_{t}=a\left(s_{t+3}-s_{t}\right)+b+e_{t} \\
& e_{t}=\xi_{t}+\lambda_{1} \xi_{t-1}+\lambda_{2} \xi_{t-2}
\end{aligned}
$$

Table 1 gives the results of this test. Since the null of unbiasedness $(a=1, b=0)$ is rejected, we can conclude that the consensus is not rational for all the currencies, hence confirming with our data the findings of the literature. In addition, since the regression coefficients are not significantly different from zero, we can also argue that the REH does not even describe the consensus over a significant sub-sample.

\section{< INSERT Table 1 here >}

We will therefore exclude the REH from our switching-regime framework. The insight behind the rejection of the REH is that processing all available information is too costly compared to the corresponding marginal gain.

We now turn to the simple processes and, as a first step, we examine in a linear model framework whether for each currency the extrapolative, adaptive and regressive components and some macroeconomic variables appear to be significant factors of the experts' forecasts. The idea is that a given component will prove significant if the forecasters have employed it, by itself or by combining it with some others, a significant number of times in the sample period. The linear model we consider is the following:

$$
\tilde{s}_{t, 3}-s_{t}=k_{0}+k_{1}\left(s_{t}-s_{t-3}\right)+k_{2}\left(\bar{s}_{t-1}-\tilde{s}_{t-1,3}\right)+k_{3}\left(\bar{s}_{t}-\bar{s}_{t-1}\right)+k_{4}\left(\tilde{s}_{t-1,3}-s_{t}\right)+\sum_{i=5} k_{i} x_{i t}+\varepsilon_{t}
$$

where the first variable term in the right-hand side represents the extrapolative component of expectations, the second and third terms an error-correction form regressive component, the fourth term the adaptive component and the last terms spreads of macroeconomic variables with respect to $\mathrm{USA}^{10}$ (all the terms are expressed in percent per quarter except the errorcorrection term of the regressive component which is expressed in percent). The target variable $\bar{s}_{t}$ is supposed to be given by the 12 months ahead expected exchange rate provided by the CF survey data, namely $\widetilde{s}_{t, 12} \cdot{ }^{11}$ We will provide later some insight about this choice. A major issue that has to be accounted for is that the European Monetary System (EMS) currencies were clearly correlated during the 1990s. ${ }^{12}$ Consequently, the Seemingly Unrelated Regression (SUR) method is applied to estimate equation (5) as a system for all currencies. Estimation results show that the intercept and the macroeconomic variables are insignificant at the 5\% level for each currency. Rejection of the intercept suggests that the systematic measurement bias is negligible. The insignificance of the interest rate differential means that experts do not refer to the Uncovered Interest Rate Parity (UIRP) when they form their expectation. By contrast, the estimated values of $k_{1}$ to $k_{4}$ are found to be significantly positive for all of the currencies. Equation (5) may thus be reduced to a combination of the three simple processes. ${ }^{13}$

A compelling approach is to estimate these parameters on pooled data across the six currencies (i.e., on 6x85=510 observations). Such an approach is of a special interest from the point of view of the switching-regression estimation, since the individual samples would not be large enough for a non-linear estimation. ${ }^{14}$ However, pooling the data requires that the value of a given parameter of the linear model is not currency-dependent, which we can check by implementing an appropriate F-test. In order to prevent biases due to possible contemporaneous correlation between residuals and heteroskedasticity, our F-test compares, 
for each currency, the unconstrained sum of squared residuals (SSR) from the SUR estimation of the system of currencies to the constrained SSR from the SUR estimation of a system where the parameters are set to be equal across currencies. Table 2 provides the value of the F-statistics for each currency:

\section{< INSERT Table 2 Here >}

It can be seen that this test fails to reject the null at the $1 \%$ level for the ITL/USD exchange rate and at the $5 \%$ level for the other currencies, thus justifying the use of pooled data. This result is not surprising, since (i) expectation parameters are rather assessed on psychological grounds and are more likely to depend on the forecaster than on the currency, (ii) at a given time, the set of experts to whom the questionnaire is sent is the same whatever the currency, and (iii) each exchange rate is defined as the price of the USD in terms of the domestic currency.

The question of the contemporaneous correlation between the EMS currencies must be examined further prior to the non-linear estimation. To evaluate the estimation bias due to this correlation, we compared the estimation results obtained with the SUR method (robust to both contemporaneous correlation and heteroskedasticity) to those provided by the cross-section Generalized Method of Moments (which is known to be robust to heteroskedasticity). Doing so, we expect to assess the bias typically related to the contemporaneous correlation. In both methods, we constrained the parameters to be equal across currencies regarding the preceding F-tests. Table 3 compares the estimated coefficients with the two methods.

\section{< INSERT Table 3 here >}

An F-test of equality of parameters is inappropriate when estimates from different methods are to be compared. However, inspection of the results leads to conclude that estimates keep generally close irrespective of the two methods, suggesting that the estimates are not affected by a significant contemporaneous correlation bias. ${ }^{15}$

Interestingly, estimation results of model (5) seem in accordance with the outcome from different questionnaire surveys conducted by Taylor and Allen (1992), Lui and Mole (1998) and Cheung and Chinn (2001) on the US foreign exchange market and Menkhoff (1997), Oberlechner (2001) and Cheung, Chinn and Marsh (2004) on European foreign exchange markets. In these questionnaire surveys, traders are asked to reveal which forecasting methods they use. As a result, short term expectations in the foreign exchange market appear to be driven by technical (or chartist) analysis whereas long term expectations, generally exceeding 6 months horizon, are mainly based on fundamentals. ${ }^{16}$ To show how the latter result applies to our data, we examine in what extent $\widetilde{s}_{12, t}$ is linked to the Purchasing Power Parity (PPP) ${ }^{17}$ and to the Uncovered Interest Rate Parity (UIRP) with constant risk premium. Consider the following model describing the UIRP hypothesis, an error correction model representing the adjustment of the spot rate towards its target and the PPP target hypothesis, respectively:

$$
\begin{aligned}
& \tilde{s}_{t, 12}-s_{t}=\eta_{0}+\eta_{1}\left(i_{t}-i_{t}^{U S}\right)+v_{1 t} \\
& s_{t}-s_{t-1}=\delta_{1}\left(\bar{s}_{t-1}-s_{t-1}\right)+\delta_{2}\left(\bar{s}_{t}-\bar{s}_{t-1}\right)+v_{2 t} \\
& \bar{s}_{t}=\theta_{0}+\theta_{1}\left(p_{t}-p_{t}^{U S}\right)
\end{aligned}
$$

where $i_{t}$ and $i_{t}^{U S}$ are long-term nominal interest rates in a European country and in USA, $p_{t}$ and $p_{t}^{U S}$ the logarithms of CPI or PPI indices. Note that (6a) does not describe an expectation 
process but an arbitrage equilibrium relation. The parameters $\eta_{1}$ and $\theta_{1}$ are expected to be equal to one while the risk premium $\eta_{0}$ and the intercept $\theta_{0}$ may take any sign. The reducedform testable equation from (6a) to (6c) gives:

$$
\tilde{s}_{t, 12}-s_{t-1}=\eta_{0}+\delta_{1}\left(\hat{\bar{s}}_{t-1}-s_{t-1}\right)+\delta_{2}\left(\hat{\bar{s}}_{t}-\hat{\bar{s}}_{t-1}\right)+\eta_{1}\left(i_{t}-i_{t}^{U S}\right)+v_{t}
$$

where $\hat{\bar{s}}_{t}=\hat{\theta}_{0}+\hat{\theta}_{1}\left(p_{t}-p_{t}^{U S}\right)$ is the pre-estimated target of the spot rate defined by the long term condition $s_{t}=\bar{s}_{t}+v_{t}$. Preliminary Johansen cointegration tests (not reported) have shown that for all countries except Ireland the spot rate and the PPP term are cointegrated at the $5 \%$ level implying that $\hat{v}_{t}$ is stationary. ${ }^{18}$ Table 4 gives the estimation results of equations (6c) and (7).

\section{< INSERT Table 4 here>}

All the slope parameters are significant and positive as expected and the significant intercept $\eta_{0}$ suggests the existence of a risk premium. The estimates of $\theta_{1}$ are often different from one, and this may be due to the fact that PPP plays only partially a target role in the spot exchange rate dynamics over the sample period. Similarly, the estimates of $\eta_{1}$ differ from one probably because of the risk-premium is time-varying and not constant as we have supposed. The low DW statistics may be interpreted as a consequence of all these missing variables. Overall, we can reasonably infer that the 3-months ahead expected exchange rate is influenced by fundamentals through the target $\widetilde{s}_{t, 12}$ included in the regressive components, and this may explain why macroeconomic variables were not found to be significant when they were introduced as additional regressors in equation (5). In fact, there is no reason to assume that each expert refers to the same target such as PPP and UIRP. The advantage of the $\widetilde{s}_{t, 12}$ target hypothesis is that it captures both individual and common factors.

\section{A Switching-Regression Model}

The analysis presented in Section 3 is based on the implicit assumption that the same expectation process prevails at any point in time. This is a special case of the theoretical framework developed in Section 2 where the individual cost/aversion ratios are timeinvariant. However, the assumption is obviously a strong one since the ratios possibly change over time, implying that each component of the process is likely to occur at a specific set of dates. Then, fitting a linear mixed model such as (5) is equivalent to imposing one or more independent variable(s) over some set of dates where the latter variable(s) is (are) not relevant. Such a piecewise overspecification will cause instability in the parameters, which cannot be eliminated unless the true sample separation is known a priori. Generally, this condition is not met and a switching-regression methodology seems to be a natural choice since it allows avoiding piecewise misspecification by selecting the most appropriate model at any time.

To test the null of parameter stability, we divided the sample by sub-samples and performed Chow tests over different sub-samples (all currencies are pooled at each date). The break points chosen were the dates of the EMS crises (namely, the widening of the fluctuation margins of the EMS exchange rate mechanism to $\pm 15 \%$ on August 1993, the exit of the U.K. and Italy from the EMS exchange rate mechanism on October 1992) or arbitrary dates (obtained by cutting off the sample into two and three equal sub-samples). In each case, the test rejected very strongly the null of stability of the parameters (see Table 5), suggesting that expectation formation possibly obeys to a change-in-regime pattern. We then assume that the 
consensus is represented at each point in time by one of the simple extrapolative, regressive and adaptive processes or some combination of them, which we define as follows.

\section{$<$ INSERT Table 5 here >}

According to the extrapolative process, the expected change in exchange rate depends on the rate of change observed during the three last months ${ }^{19}$ :

$$
\tilde{s}_{t, 3}-s_{t}=\alpha_{1}+\gamma\left(s_{t}-s_{t-3}\right)+\varepsilon_{1 t}
$$

where $\varepsilon_{1 t}$ is a stochastic error term. Although the theoretical sign of the parameter $\gamma$ is more likely to be positive, a negative value is conceivable in the extent that it can reflect a naive regressive process (systematic turning tendency).

The adaptive process says that the expected change in exchange rate is based on an "early revision" mechanism of forecast errors that we formulate as follows:

$$
\widetilde{s}_{t, 3}-s_{t}=\alpha_{2}+(1-\beta)\left(\tilde{s}_{t-1,3}-s_{t}\right)+\varepsilon_{2 t}
$$

where $0 \leq \beta \leq 1$. In a standard adaptive model, the time horizon corresponds to the frequency of observations, which is not the case with our data. But it is possible - indeed very likely that experts will not wait until the three month horizon is completed to revise their expectations. When, during the survey procedure, the spot rate at the beginning of the month is known, the individuals will probably compare this rate to the exchange rate which they had expected during the last survey, i.e., a month before, and not three months before as the standard adaptive model assumes. ${ }^{20}$ This assumption is supported by the fact that the early revision model defines $\tilde{s}_{t, 3}$ as a weighted average of past monthly values of $s_{t}$, while the standard adaptive model defines $\tilde{s}_{t, 3}$ as a weighted average of past quarterly values of $s_{t}$. Hence, with our data, equation (9) seems more appropriate than the standard model.

In the case of the regressive process, the expected change in exchange rate is represented by a simple error correction model (ECM):

$$
\tilde{s}_{t, 3}-s_{t}=\alpha_{3}+\mu_{1}\left(\tilde{s}_{t-1,12}-\tilde{s}_{t-1,3}\right)+\mu_{2}\left(\tilde{s}_{t, 12}-\tilde{s}_{t-1,12}\right)+\left(\tilde{s}_{t-1,3}-s_{t}\right)+\varepsilon_{3 t}
$$

where $0 \leq \mu_{i} \leq 1(i=1,2) .{ }^{21}$ According to (10), the expectation $\widetilde{s}_{t, 3}$ converges towards its target value $\tilde{s}_{t, 12}$ (when $\alpha_{3}=0$ ), while in the adaptive model (9), $\tilde{s}_{t, 3}$ converges towards the observed value $s_{t}$ (when $\alpha_{2}=0$ ). Therefore, the adaptive process is not, here, a particular case of the error-correction model as it is stated by the standard adjustment process.

The extrapolative-regressive process is defined as the weighted average of the deterministic components of (8) and (10), namely:

$$
\begin{aligned}
\tilde{s}_{t, 3}-s_{t}= & a \alpha_{1}+(1-a) \alpha_{3}+a \gamma\left(s_{t}-s_{t-3}\right)+(1-a) \mu_{1}\left(\tilde{s}_{t-1,12}-\tilde{s}_{t-1,3}\right) \\
& +(1-a) \mu_{2}\left(\tilde{s}_{t, 12}-\tilde{s}_{t-1,12}\right)+(1-a)\left(\tilde{s}_{t-1,3}-s_{t}\right)+\varepsilon_{4 t}
\end{aligned}
$$

where $0<a<1$. Note that the error term $\varepsilon_{4 t}$ is not defined as a weighted average of the errors of the extrapolative and regressive processes because this would imply that the 2-mixed process (11) would coexist with the two simple processes at the same time, and this is not consistent with our framework. Indeed, the only fact that a given error term exists implies that 
the corresponding generating process exists. As (11) involves two simple processes, we will also refer to it with the name "2-mixed process". The same remarks hold for the other mixed processes presented below.

Weighting the deterministic components of (8) and (9), we get the extrapolativeadaptive process:

$$
\tilde{s}_{t, 3}-s_{t}=b \alpha_{1}+(1-b) \alpha_{2}+b \gamma\left(s_{t}-s_{t-3}\right)+(1-b)(1-\beta)\left(\tilde{s}_{t-1,3}-s_{t}\right)+\varepsilon_{5 t}
$$

where $0<b<1$. The regressive-adaptive process is the weighted average of the deterministic components of (9) and (10):

$$
\begin{aligned}
\tilde{s}_{t, 3}-s_{t}= & c \alpha_{3}+(1-c) \alpha_{2}+c \mu_{1}\left(\tilde{s}_{t-1,12}-\tilde{s}_{t-1,3}\right)+c \mu_{2}\left(\tilde{s}_{t, 12}-\tilde{s}_{t-1,12}\right) \\
& +[c+(1-c)(1-\beta)]\left(\tilde{s}_{t-1,3}-s_{t}\right)+\varepsilon_{6 t}
\end{aligned}
$$

where $0<c<1$. Finally, the extrapolative-regressive-adaptive process, which we have already estimated as a linear model (see Table 3), is defined as a weighted average of the deterministic components of (8), (9) and (10), so that:

$$
\begin{aligned}
\tilde{s}_{t, 3}-s_{t}= & d_{1} \alpha_{1}+d_{2} \alpha_{3}+d_{3} \alpha_{2}+d_{1} \gamma\left(s_{t}-s_{t-3}\right)+d_{2} \mu_{1}\left(\tilde{s}_{t-1,12}-\tilde{s}_{t-1,3}\right) \\
& +d_{2} \mu_{2}\left(\tilde{s}_{t, 12}-\tilde{s}_{t-1,12}\right)+\left[d_{2}+d_{3}(1-\beta)\right]\left(\tilde{s}_{t-1,3}-s_{t}\right)+\varepsilon_{7 t}
\end{aligned}
$$

where $0<d_{i}<1, i=1,2,3$ and $d_{1}+d_{2}+d_{3}=1$. We call this process a "3-mixed process".

The stochastic error term $\varepsilon_{k t}(\mathrm{k}=1, \ldots, 7)$ of each process is defined over the subsample concerned by this process and is supposed to be $\operatorname{Nid}\left(0, \sigma_{k}^{2}\right)$ on each point of this subsample. The aim of the empirical exercice presented hereafter is precisely to identify the process that is likely to be used by the respondents at each date. Which rule governs the regime selection? Such a rule is explicitly specified in threshold autoregressive (TAR) models (Tong, 1990) or smooth transition autoregressive (STAR) models (Chan and Tong, 1986; Teräsvirta, 1994). In these approaches, the regime switch is governed by the values taken by a threshold variable (in TAR models) or a transition variable (in STAR models) with respect to constant thresholds to be estimated. However, when applied to our framework, two conceptual difficulties arise with these methodologies. First, none of them - and especially the STAR model - is appropriate to estimate models with a high number of regimes such as our model with seven regimes in operation. Second, in our context, there is no observable threshold variable governing the change. The most intuitive choice would be the cost/aversion ratio discussed in Section 2 but this variable is not known to the investigator although it is supposed to be known to the forecasters. This unobserved selection rule is then replaced in the model by an unknown probability associated with each process and which is to be estimated. At this stage, we can specify this probability either as the unconditional constant probability associated with a given state from a "mixture of normal distributions" (Everitt and Hand, 1981; Quandt and Ramsey, 1992) or as the probability that $\widetilde{s}_{t, 3}-s_{t}$ came from a given regime conditional on the information at time t-1 (filtered inference) as introduced in Markovswitching models (Engel and Hamilton, 1990; Hamilton, 1990, 1994). We choose the first approach for two reasons. On the one hand, assessing the standard probability distribution of the competing regimes over the sample period (that is, the structural probabilities associated with different regimes) is sufficient to deduce what regime is in operation at any time and, more generally, whether or not expectations change over time. On the other hand, the efficient estimation of the 49 transition probabilities involved in a seven-regime Markov model would require a very large sample size, if it would not simply be unfeasible. 
We thus represent the expectation formation behavior using a "mixture"-type model, also called in the literature "regression model with stochastic choice of regimes", and first suggested by Goldfeld and Quandt (1973). The model is the following:

$$
\tilde{s}_{t, 3}-s_{t}= \begin{cases}\text { extrapolative process (8) } & \text { with probability } \lambda_{1} \\ \text { adaptive process (9) } & \text { with probability } \lambda_{2} \\ \text { regressive process (10) } & \text { with probability } \lambda_{3} \\ \text { extrapolative - regressive process (11) } & \text { with probability } \lambda_{4} \\ \text { extrapolative - adaptive process (12) } & \text { with probability } \lambda_{5} \\ \text { regressive - adaptive process (13) } & \text { with probability } \lambda_{6} \\ \text { extrapolative - regressive - adaptive process (14) } & \text { with probability } \lambda_{7}\end{cases}
$$

where the $\lambda^{\prime} s$ stand for the unconditional probabilities (according to Bayes's theorem, this is the prior probability of the process) which verify the conditions $\sum_{k=1}^{7} \lambda_{k}=1$, and $0 \leq \lambda_{k} \leq 1 \forall k=1, \ldots, 7$. Note that if the field of possible processes were limited to the three simple ones only (i.e., equations (8) to (10)), the possibility for the consensus to be represented by a mixed model would vanish. This is because model (15) is based upon the hypothesis that one and only one regime operates at any time, so that the only way of allowing the switching regression model to select a mixed process is to include this process among the states of the nature. According to our model, if the forecasters generate their expectations by an alternation of the simple processes only, then the unconditional probabilities associated with all the mixed processes will necessarily be insignificant. Similarly, if forecasters only employ mixed processes, the simple processes will be insignificant.

\section{Empirical Results}

We have shown, in Section 3 (second sub-section), that the parameters of the expectation process can be supposed to be currency-invariant. Hence, the switching-regime model (15) can be estimated by pooling the six currencies over the period June 1990 to June 1997 (510 observations). The model (15) is estimated using the Full Information Maximum Likelihood (FIML) method. $^{22}$

The 25 parameters involved in model (15) are initialized as follows. The structural parameters $\gamma, \mu_{1}, \mu_{2}$ and $\beta$ have been initialized using the SUR estimates (Table 3). Given the latter, the initial values of the intercepts $\alpha_{1}, \alpha_{2}$ and $\alpha_{3}$ have been calculated as the mean of the part of the expected change in exchange rate not explained by the independent variable in the case of each simple process. The weighs $a, b, c, d_{1}$ and $d_{2}\left(d_{3}\right.$ being subject to the constraint $d_{1}+d_{2}+d_{3}=1$ ) have been initialized arbitrarily as $0.5,0.5,0.5,0.333$, and 0.333, respectively. The starting values of the unconditional probabilities $\lambda_{1}$ to $\lambda_{6}$ ( $\lambda_{7}$ being obtained from $\sum_{k=1}^{7} \lambda_{k}=1$ ) are calculated as the frequency of each process in providing the lowest squared residuals over the pooled sample, given the initial values of the other parameters. ${ }^{23}$ The standard-deviations $\sigma_{1}$ to $\sigma_{7}$ are given starting values by (i) generating a sub-sample for each process according to the minimal residuals criterion and (ii) computing 
the empirical standard-error of the residual term of each process over its initial sub-sample. Table 6 provides the estimated values of the parameters.

\section{< INSERT Table 6 here >}

We gauge the significance of the maximum likelihood estimates by applying a Wald test. The estimated structural coefficients $\hat{\gamma}, \hat{\mu}_{1}, \hat{\mu}_{2}, \hat{\beta}$, the weights $\hat{a}, \hat{b}, \hat{c}, \hat{d}_{1}, \hat{d}_{2}$ and the unconditional probabilities $\hat{\lambda}_{i}$ are significant at the $5 \%$ level and fall within the theoretical interval $[0,1]$. The significance of the intercepts denotes the presence of measurement biases imbedded in the survey data (see sub-section Data, Section 3). All the components in a given mixed process have non-zero weights, suggesting that none of the components is negligible. The estimate $\widehat{\beta}=0.603$ in the adaptive term says that the average delay of influence of past values of $s_{t}$ is about 20 days $((1-\hat{\beta}) / \hat{\beta}=0.66$ month), which seems a rather realistic value. Interestingly, the positive value of the extrapolative parameter $\hat{\gamma}$ preserves the sign of the actual change in the spot rate, and this result is all the more satisfactory since the literature generally finds a significant negative value (Bénassy-Quéré, Larribeau and MacDonald, 2003), which gives in fact a kind of regressive process. None of the simple extrapolative, regressive and adaptive processes is affected by a significant unconditional probability. This is because the sub-samples concerned by these processes are not large enough to allow significant estimates of the associated probabilities and standard errors at even the $10 \%$ level (an exception is the adaptive process which occurs slightly more frequently). ${ }^{24}$ By contrast, the sum of the unconditional probabilities associated with the four mixed processes exceeds 0.9 , and the probability of the extrapolative-regressive-adaptive model is roughly equal to the sum of the probabilities of the three 2-mixed processes. These findings clearly suggest that forecasters do not rely on simple processes and mix systematically the forecasting methods. ${ }^{25}$

Using the estimated unconditional probabilities and by an application of Bayes' rule we can calculate the conditional probabilities associated with the seven processes at a given time. ${ }^{26}$ Figure 1 displays the conditional probabilities of each process for each currency (the simple extrapolative process with zero probabilities has not been represented).

\section{< INSERT Figure 1 here>}

Inspection of the seven conditional probabilities at each point in time shows that the highest probability very often dominates the sum of the six other probabilities (otherwise it dominates them with a substantial gap), and this confers some reliance to the "winner" process at each time. It seems useful to evaluate the accuracy of the regime switching model with respect to the permanent 3-mixed process by comparing the standard errors of the residuals obtained with the two models. We computed the standard error of the switching regression model on the basis of the (minimum) residuals given by the winner processes over the sample. The standard error of regression corresponding to the linear model is 0.01 while the one of the non-linear model is 0.006 . This shows that the residual variance of the linear model is almost equal to 3 times the one of the switching regime model. The important improvement of the quality of the fit suggests that the hypothesis that the forecast function is unchangingly the same over time must be rejected. The pattern of conditional processes shows that, besides the huge frequency of the four mixed processes (99.4\%), changes in processes occur very often (43.8\%). Because agents shift almost exclusively from a mixed process to another mixed process, the persistence of one or several components over two successive points in time denotes a substantial inertia in expectation behavior. ${ }^{27}$ Such an inertia would mean that the amount of information processed by forecasters follows a 
smoothly changing time pattern. It can be seen from Figure 1 that changes in processes occur not only over time for a given currency but also across currencies at a given date, ${ }^{28}$ and this suggests that forecasters do not necessarily form their expectations in the same way according to currencies. Overall, the time-instability of the estimates in the linear regression model (5) reported above may be viewed as a result of these two dimensions inherent to change in expectation processes.

\section{Concluding Remarks}

In the light of the economically rational expectations theory where the cost and advantage of information are time-varying and differ across agents, this paper relaxes two hypotheses commonly accepted in the literature: (i) the same expectation process prevails at any time, and (ii) this unique process is either a representation of the rational expectation hypothesis or one of the simple extrapolative, adaptive or regressive expectation schemes, the latter capturing the influence of fundamentals through the target. Using six series of European exchange rate expectations relative to US Dollar provided by Consensus Forecasts, we checked first that the consensus provides no indication of rationality. We then assumed that agents form their expectations by choosing some combination of the three simple processes and allowed them to change this combination over time and across currencies. We tested these hypotheses using a switching-regression model with stochastic choice of regime and suggested an interpretation in terms of an individual mixing effect and of a groupheterogeneity effect. We found that both the hypotheses of mixed expectation processes and of change in processes are validated by the data. The fact that the simple processes do never occur contradicts most of the approaches in the literature on expectations formation where one of these processes is generally assumed to hold at any time.

\section{REFERENCES}

Allen, Helen and Mark P. Taylor, "Charts, Noise and Fundamentals in the London Foreign Exchange Market”, The Economic Journal 100 (1990): 49-59.

Baillie, Richard T. and Patrick C. McMahon, The Foreign Exchange Market : Theory and Econometric Evidence, Cambridge: Cambridge University Press, 1992.

Barberis, Nicholas, Ming Huand and Tano Santos, "Prospect Theory and Asset Prices", Quarterly Journal of Economics 116 (2001): 1-53.

Bénassy-Quéré, Agnès, Sophie Larribeau and Ronald MacDonald, "Models of Exchange Rate Expectations : How Much Heterogeneity ?” Journal of International Financial Markets, Institutions \& Money 13(2) (2003): 113-36.

Bessec, Marie and François-Mathieu Robineau, "Comportements Chartistes et Fondamentalistes : Coexistence ou Domination Alternative sur le Marché des Changes”, Revue Economique 54(6), November (2003): 1213-38.

Calvo, Guillermo A. and Carlos A. Rodriguez, “A Model of Exchange Rate Determination under Currency Substitution and Rational Expectations”, Journal of Political Economy 85(3) (1977): 617-26.

Chan, K.S. and H.Tong, “On Estimating Thresholds in Autoregressive Models”, Journal of Time Series Analysis 7 (1986): 179-90. 
Cheung, Yin-Wong and Menzie D. Chinn, "Currency Traders and Exchange Rate Dynamics: a Survey of the US Market”, Journal of International Money and Finance 20(4) (2001): 439-71.

Cheung, Yin-Wong, Menzie D. Chinn and Ian W. Marsh, "How Do UK-Based Foreign Exchange Dealers Think Their Market Operates?”, International Journal of Finance and Economics 9(4) (2004): 289-306.

Chinn, Menzie D. and Jeffrey A. Frankel, "More Survey Data on Exchange Rate Expectations: More Currencies, More Horizons, More Tests”, in: W.Allen and D. Dickinson (editors), Monetary Policy, Capital Flows and Financial Market Developments in the Era of Financial Globalisation: Essays in Honour of Max Fry, Routledge, 2002, pp. 145-67.

Engel, Charles and James D. Hamilton, "Long Swings in the Dollar : Are They in the Data and Do Markets Know It?”, American Economic Review 80(4) (1990): 689-713.

Everitt, B.S. and D.J. Hand, Finite Mixture Distributions, London: Chapman and Hall, 1981.

Feige, Edgar L. and Douglas K. Pearce, "Economically Rational Expectation: Are Innovations in the Rate of Inflation Independent of Innovations in the Measures of Monetary and Fiscal Policy”, Journal of Political Economy 84(3), June (1976): 499-522.

Frankel, Jeffrey A. and Kenneth A. Froot, "Understanding the US Dollar in the Eighties: The Expectations of Chartists and Fundamentalists", The Economic Record, special issue (1986): 24-38.

“Using Survey Data to Test Propositions Regarding Exchange Rate Expectations”, American Economic Review 1(77), March (1987): 133-53.

"Chartists, Fundamentalists and Trading in the Foreign Exchange Market", American Economic Review 80(2), May (1990): 181-5.

Goldfeld, Stephen M. and Richard E. Quandt, "The Estimation of Structural Shifts by Switching Regression”, Annals of Economics and Social Measurement 2(4) (1973): 47585.

Hamilton, James D., “Analysis of Time Series Subject to Changes in Regime”, Journal of Econometrics 45(1-2) (1990): 39-70.

, Time series analysis, Princeton, New Jersey: Princeton University Press, 1994

Harvey, John T., "The Nature of Expectations in the Foreign Exchange Market: a Test of Competing Theories”, Journal of Post Keynesian Economics 21(2) (1999): 181-201.

Holden, Kenneth, David A. Peel and J.L. Thompson, Expectations: Theory and Evidence, New-York: St Martin Press, 1985.

Ito, Takatoshi, "Foreign Exchange Rate Expectations: Micro Survey Data”, American Economic Review 80(3) (1990): 434-49.

"Short-Run and Long-Run Expectations of the Yen/Dollar Exchange Rate", Journal of the Japanese and International Economies 8(2) (1994): 119-43.

Johnston, Jack., Econometric Methods, Tokyo : McGraw-Hill, 1963.

Kaminsky, Graciela, "Is There a Peso Problem? Evidence from the Dollar/Pound Exchange Rate, 1976-1987”, American Economic Review 83(3) (1993): 450-72.

Krugman, Paul R., "Target Zones and Exchange Rate Dynamics”, Quarterly Journal of Economics 106(3) (1991): 669-82.

Lui, Yu-Hon and David Mole, "The Use of Fundamental and Technical Analyses by Foreign Exchange Dealers: Hong Kong Evidence”, Journal of International Money and Finance 17(3) (1998): 535-45

MacDonald, Ronald, “Are Foreign Exchange Market Forecasters Rational? Some Survey Based Tests", The Manchester School of Economic and Social Studies 58, June (1991): 229-41.

"Expectations Formation and Risk in Three Financial Markets: Surveying What Survey Say”, in: François Gardes and Georges Prat (editors), Price Expectations in Goods 
and Financial Markets: New developments in theory and empirical research, Cheltenham,UK; Northampton, MA, USA: Edward Elgar, 2000, pp. 172-212.

MacDonald, Ronald and Ian W MARSH, "Currency Forecasters are Heterogeneous: Confirmation and Consequences”, Journal of International Money and Finance 15 (1996): 665-85.

Menkhoff, Lukas, "Examining the Use of Technical Currency Analysis", International Journal of Finance and Economics 2(4) (1997): 307-18.

Mussa, Michael, "The Exchange Rate, the Balance of Payments and Monetary and Fiscal Policy under a Regime of Controlled Floating”, Scandinavian Journal of Economics 78(2) (1976): 229-48

Muth, John F., “Optimal Properties of Exponentially Weighted Forecasts”, Journal of the American Statistical Association, June (1960): 299-306.

, "Rational Expectations and the Theory of Price Movements", Econometrica 29, July (1961): 315-35.

Oberlechner, Thomas, "Importance of Technical and Fundamental Analysis in the European Exchange Market”, International Journal of Finance and Economics 6(1) (2001): 81-93.

Prat, Georges and Remzi Uctum, "The Evidence of a Mixed Expectation Generating Process in the Foreign Exchange Market”, in: François Gardes and Georges Prat (editors), Price Expectations in Goods and Financial Markets: New developments in theory and empirical research, Cheltenham,UK; Northampton, MA, USA: Edward Elgar, 2000, pp. 251-70

Quandt, Richard E., “A New Approach to Estimating Switching Regressions”, Journal of the American Statistical Association 67(338) (1972): 306-10.

Quandt, Richard E. and James B. Ramsey, "Estimating Mixtures of Normal Distributions and Switching Regressions", The collected essays of Richard E. Quandt, Volume 1, Economists of the Twentieth Century series, Aldershot, U.K.: Elgar, 1992, pp. 180-203.

Takagi, Shinji, "Exchange Rate Expectations, a Survey of Survey Studies”, IMF Staff Papers 38(1) (1991): 156-83.

Taylor, Mark P. and Helen Allen, "The Use of Technical Analysis in the Foreign Exchange Market”, Journal of International Money and Finance 11(3) (1992): 304-14.

Teräsvirta, Timo, "Specification, Estimation, and Evaluation of Smooth Transition Autoregressive Models”, Journal of the American Statistical Association 89 (1994): 20818.

Tong, Howell, Nonlinear Time Series : a Dynamical Systems Approach, New-York: Oxford University Press, 1990.

Vigfusson, Robert, "Switching Between Chartists and Fundamentalists : a Markov RegimeSwitching Approach”, International Journal of Financial Economics 2 (1997): 291-205 


\begin{tabular}{ccccccc}
\hline Currencies & $a$ & $B$ & $\lambda_{1}$ & $\lambda_{2}$ & $\bar{R}^{2}$ & $D W$ \\
\hline FRF/USD & 0.007 & 0.001 & 0.46 & 0.14 & 0.19 & 1.91 \\
& $(0.9)$ & $(4.9)$ & $(4.2)$ & $(1.2)$ & & \\
DEM/USD & 0.019 & 0.013 & 0.35 & 0.18 & 0.17 & 1.86 \\
& $(0.8)$ & $(4.7)$ & $(3.3)$ & $(1.7)$ & & \\
ITL/USD & 0.000 & 0.013 & 0.46 & 0.03 & 0.14 & 1.97 \\
& $(1.0)$ & $(4.6)$ & $(4.1)$ & $(0.3)$ & & \\
DKK/USD & 0.005 & 0.018 & 0.35 & 0.23 & 0.19 & 1.84 \\
& $(0.5)$ & $(5.0)$ & $(3.3)$ & $(2.1)$ & & \\
GBP/USD & 0.09 & 0.01 & 0.45 & -0.11 & 0.08 & 2.08 \\
& $(1.8)$ & $(5.8)$ & $(3.9)$ & $(-1.0)$ & & \\
IEP/USD & 0.12 & 0.02 & 0.32 & 0.03 & 0.07 & 1.97 \\
& $(1.3)$ & $(5.9)$ & $(2.9)$ & $(0.3)$ & & \\
\hline
\end{tabular}

Estimates are those of equation (4). The numbers in brackets are the Student's tvalues.

Table 1. Unbiasedness Tests

\begin{tabular}{lcccccc}
\hline Currencies & FRF/USD & DEM/USD & ITL/USD & DKK/USD & GBP/USD & IEP/USD \\
\hline F-statistic & $0.22^{*}$ & $1.03^{*}$ & $3.01^{* *}$ & $0.97^{*}$ & $2.41^{*}$ & $0.43^{*}$ \\
\hline
\end{tabular}

The critical values of $\mathrm{F}$ for 4 and 80 d.o.f. are 2.48 and 3.56 at the $5 \%$ and $1 \%$ significance level, respectively. If $\mathrm{F}$ exceeds the critical value, the null of equality of parameters is rejected. * and ** indicate a non-rejection of the null at the $5 \%$ and $1 \%$ significance level, respectively. The F-statistic is calculated using the SSRs from the SUR estimation.

Table 2. Test F of Equality of Parameters Across Currencies

\begin{tabular}{ccccc}
\hline Parameters & $k_{1}$ & $k_{2}$ & $k_{3}$ & $k_{4}$ \\
\hline Seemingly Unrelated & 0.06 & 0.20 & 0.18 & 0.46 \\
Regression method & $(0.01)$ & $(0.02)$ & $(0.01)$ & $(0.01)$ \\
Cross-section Generalized & 0.08 & 0.17 & 0.20 & 0.49 \\
Method of Moments & $(0.01)$ & $(0.02)$ & $(0.01)$ & $(0.01)$ \\
\hline
\end{tabular}

Estimates refer to the parameters of equation (5) reduced to its significant components. The standard-deviations are given in brackets. Both methods estimate a system of currency-specific equations where the parameters are constrained to be unchanged across currencies.

Table 3. Measuring the Contemporaneous Correlation Bias 


\begin{tabular}{ccccccccc}
\hline Currencies & $\theta_{0}$ & $\theta_{1}$ & $\eta_{0}$ & $\eta_{1}$ & $\delta_{1}$ & $\delta_{2}$ & $\bar{R}^{2}$ & $D W$ \\
\hline FRF/USD & 2.11 & 0.95 & 0.03 & 0.61 & 0.22 & 12.45 & 0.40 & 0.71 \\
& $(12.6)$ & $(2.5)$ & $(5.7)$ & $(5.2)$ & $(4.3)$ & $(2.6)$ & & \\
DEM/USD & 0.65 & 0.72 & 0.03 & 0.76 & 0.32 & 3.72 & 0.46 & 0.73 \\
& $(6.5)$ & $(1.9)$ & $(7.5)$ & $(6.6)$ & $(6.4)$ & $(1.8)$ & & \\
ITL/USD & 8.15 & 2.19 & -0.02 & 1.03 & 0.13 & 1.25 & 0.47 & 1.49 \\
& $(108.2)$ & $(11.7)$ & $(-2.6)$ & $(7.5)$ & $(3.1)$ & $(2.0)$ & & \\
DKK/USD & 2.24 & 0.82 & 0.02 & 1.10 & 0.26 & 21.2 & 0.49 & 0.63 \\
& $(11.6)$ & $(2.2)$ & $(5.4)$ & $(8.4)$ & $(4.7)$ & $(3.6)$ & & \\
GBP/USD & 0.05 & 0.60 & 0.02 & 0.23 & 0.16 & 3.79 & 0.21 & 1.00 \\
& $(0.9)$ & $(9.2)$ & $(3.1)$ & $(1.5)$ & $(2.9)$ & $(3.1)$ & & \\
IEP/USD & 0.32 & 2.0 & 0.03 & 0.62 & 0.25 & 1.76 & 0.50 & 0.59 \\
& $(3.0)$ & $(7.5)$ & $(4.9)$ & $(6.4)$ & $(3.5)$ & $(3.5)$ & & \\
\hline
\end{tabular}

Estimates are those of equations (6c) and (7). The numbers in brackets are the Student's t-values. The seasonally adjusted price indices are CPI for France and Denmark and PPI otherwise. Interest rates are 12-month maturity Euro-money rates for all countries except for Ireland, for which 12-month Interbank interest rates have been used.

Table 4. 12-Month Ahead Expected Exchange Rate , PPP and UIRP

\begin{tabular}{ccccc}
\hline Break & $\begin{array}{c}\text { October 1992 } \\
\text { (exit of UK and } \\
\text { point(s) }\end{array}$ & $\begin{array}{c}\text { August 1993 } \\
\text { (widening of the }\end{array}$ & $\begin{array}{c}\text { December 1993 } \\
\text { (2 equal } \\
\text { sub-periods) }\end{array}$ & $\begin{array}{c}\text { Sep.1992, Feb.1995 } \\
\text { (3 equal } \\
\text { sub-periods) }\end{array}$ \\
\hline F & 2.60 & 2.56 & 3.68 & 7.83 \\
LR & 10.44 & 10.30 & 14.74 & 60.40 \\
\hline
\end{tabular}

F and LR denote the F-statistic and the log-likelihood ratio statistic, which have F-distribution and an asymptotic $\chi^{2}$ distribution under the null of stability, respectively. For 2 sub-periods $\mathrm{F}(4,77)=2.48$ and $\chi^{2}(4)=9.48$ and for 3 sub-periods $\mathrm{F}(8,73)=2.07$ and $\chi^{2}(8)=15.51$ at the $5 \%$ level. The parameters concerned by the tests have been estimated with OLS and using pooled data.

Table 5. The Chow Tests of the Null of Parameter Stability 


\begin{tabular}{|c|c|c|c|}
\hline Parameters & $\begin{array}{c}\text { ML } \\
\text { Estimates }\end{array}$ & $\begin{array}{c}\text { Standard } \\
\text { deviations }\end{array}$ & $\begin{array}{c}\text { Wald } \\
\text { Statistics }\end{array}$ \\
\hline \multicolumn{4}{|c|}{ Structural parameters } \\
\hline$\gamma$ & 0.157 & 0.033 & 22.5 \\
\hline$\mu_{1}$ & 0.383 & 0.036 & 113.4 \\
\hline$\mu_{2}$ & 0.698 & 0.029 & 591.4 \\
\hline$\beta$ & 0.603 & 0.063 & 90.8 \\
\hline \multicolumn{4}{|c|}{ Intercepts } \\
\hline$\alpha_{1}$ & 0.014 & 0.002 & 46.1 \\
\hline$\alpha_{2}$ & -0.010 & 0.002 & 29.2 \\
\hline$\alpha_{3}$ & 0.005 & 0.002 & 6.3 \\
\hline \multicolumn{4}{|c|}{ Weightings $(a)$} \\
\hline$a$ & 0.501 & 0.021 & 589.7 \\
\hline$b$ & 0.371 & 0.153 & 5.9 \\
\hline$c$ & 0.522 & 0.046 & 127.0 \\
\hline$d_{1}$ & 0.306 & 0.057 & 28.6 \\
\hline$d_{2}$ & 0.266 & 0.017 & 253.9 \\
\hline \multicolumn{4}{|c|}{ Standard-errors of residuals } \\
\hline$\sigma_{1}$ & 0.011 & (b) & (b) \\
\hline$\sigma_{2}$ & 0.014 & 0.009 & 2.2 \\
\hline$\sigma_{3}$ & 0.002 & 0.003 & 0.4 \\
\hline$\sigma_{4}$ & 0.003 & 0.001 & 17.2 \\
\hline$\sigma_{5}$ & 0.011 & 0.003 & 14.9 \\
\hline$\sigma_{6}$ & 0.007 & 0.001 & 37.3 \\
\hline$\sigma_{7}$ & 0.005 & 0.0006 & 77.4 \\
\hline \multicolumn{4}{|c|}{ Unconditional probabilities (c) } \\
\hline$\lambda_{1}$ & 0 & (b) & (b) \\
\hline$\lambda_{2}$ & 0.042 & 0.09 & 0.2 \\
\hline$\lambda_{3}$ & 0.012 & 0.01 & 1.5 \\
\hline$\lambda_{4}$ & 0.152 & 0.04 & 14.3 \\
\hline$\lambda_{5}$ & 0.163 & 0.092 & 3.2 \\
\hline$\lambda_{6}$ & 0.188 & 0.045 & 17.4 \\
\hline
\end{tabular}

Results are obtained from the maximization of the likelihood function associated to model (15) over the period 1990.06 to 1997.06 for the 6 currencies (510 pooled data). The null hypothesis of zero coefficient is rejected if the Wald statistics exceeds $\chi^{2}(1$, $\alpha$ ) which equals $6.63,3.84,2.71$ at the $\alpha=1 \%, 5 \%, 10 \%$ significance levels, respectively. (a) $\hat{d}_{3}=1-\hat{d}_{1}-\hat{d}_{2}=0.428$. (b) The auxiliary parameters for $\lambda_{1}$ were not found to be significantly different from zero, which implies that $\hat{\lambda}_{1}=0$ (see footnote 23); hence one cannot estimate $\sigma_{1}$ because the sub-sample of the extrapolative process is empty; (c) $\hat{\lambda}_{7}=1-\sum_{i=1}^{6} \hat{\lambda}_{i}=0.443$.

Table 6. Estimation Results for the Switching-Regime Expectation Model 

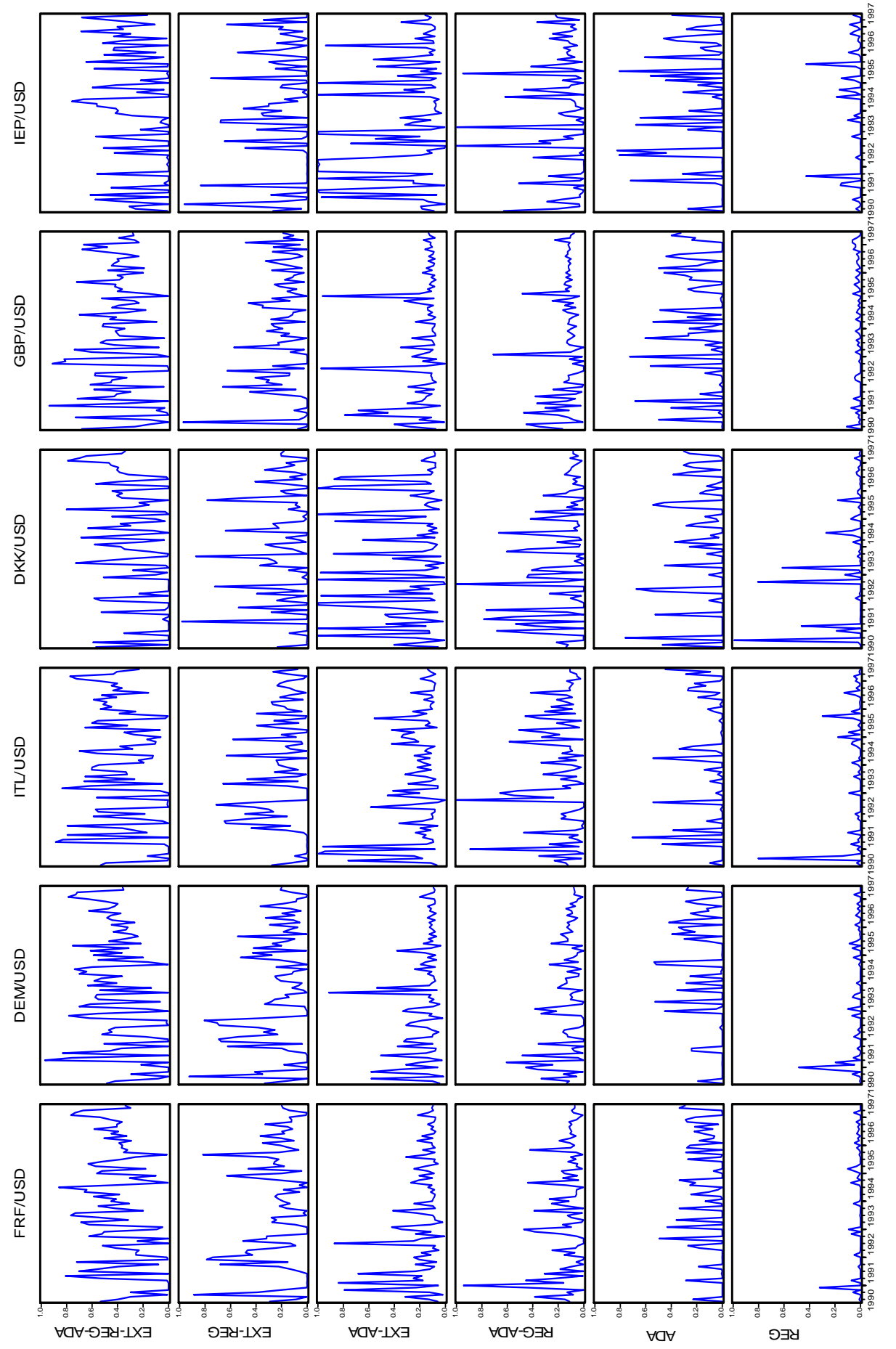

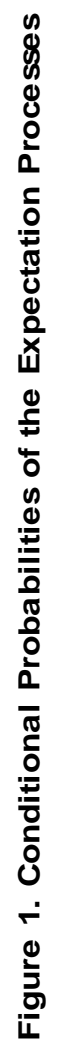




\section{FOOTNOTES}

1 See, among others, Mussa (1976) for the flexible-price monetary model, Calvo and Rodriguez (1977) for the currency substitution model, Krugman (1991) for the target zone model, and Harvey (1999) for the post-keynesian model.

${ }^{2}$ Since the states of the nature and the associated "true" probabilities are known to each of the rational agents, all of them compute the same mathematical expectation.

${ }^{3}$ Examples of types of information are actual and passed values of the variable to be forecasted, of observed stochastic shocks, and of macroeconomic variables.

${ }^{4}$ Our theoretical approach keeps the spirit of Feige and Pearce (1976) model but differs from it on two major points: (i) we relate the information used to the expected quadratic error and not to the ex-post quadratic error, so that $f$ is clearly a behavioral function; (ii) we relax the assumption that informational costs and amounts of information are constant over time and allow these magnitudes to be time-varying.

${ }^{5}$ In the stock market, for example, an explanation of the equity premium puzzle is given by the dependence of the risk aversion vis-à-vis the state of the nature (Barberis, Huand and Santos, 2001).

${ }^{6}$ Although provided by the CF surveys, we did not include among our EMS currencies the Dutch guilder and the Belgian franc since over the period considered these were linked to the German mark with fixed parities.

${ }^{7}$ This day is the first Monday of the month until March 1994 and the second one afterwards with the exception of holidays, in which case the closest working day is applicable. However the effective horizons always remain equal to 3 and 12 months. If, for instance, the answers are due on the 3rd of May (which was the case in May 1993), the future values are asked for August 3, 1993 (3 month-ahead expectations) and for January 3, 1994 (12 month-ahead expectations).

${ }^{8}$ Under these conditions, it can be shown that the market expectations model can be written in terms of the consensus expectations model plus a MA(1) term representing the random components of the measurement error when the lagged endogenous variable appears as a regressor.

${ }^{9}$ For each point in time and for each currency, the cross-section coefficient of variation (i.e., the ratio of the standard deviation of individual answers and the consensus) lies between 3\% and $4 \%$ for the 3-month horizon and between $5 \%$ and $8 \%$ for the 12 -month horizon. This indicates that the heterogeneity of individual expectations is neither negligible, nor large enough for the consensus to be irrelevant.

10 These are observed and expected values of short term interest rates and inflation rates, and observed changes in industrial productions and in money supplies.

${ }^{11}$ We attempted to proxy the target with the PPP represented by $\bar{s}_{t}=a \ln \left(P_{t} / P_{t}^{U S}\right)+c$, where $P_{t}$ and $P_{t}^{U S}$ represent CPI or PPI for a given European country and for USA respectively, and $c$ is the mean of $s_{t}-\ln \left(P_{t} / P_{t}^{U S}\right)$. For all currencies the regressive components in (5) were found to be rejected.

12 The average of the 21 coefficients of determination between the series of expected change in exchange rate for the six currencies is 0.53 .

${ }^{13}$ The standard error of the 3-mixed model is 0.01 while the ones of the simple extrapolative, adaptive and regressive models are $0.019,0.015$ et 0.022 , respectively. It is not necessary to implement here specification tests, such as the likelihood ratio tests, to prove that the 3-mixed model outperforms the 3 simple models since all the components of the 3-mixed model are found to be significant. 
${ }^{14}$ This condition is even more necessary if the switching model involves processes which overlap each other in terms of their specifications (Quandt, 1972, p.308), this being the case with our seven processes (see below).

${ }^{15}$ Similarly to the unbiasedness tests (Table 1), the introduction of a MA(2) specification of the residuals in the case of each currency did not alter the OLS estimates of equation (5), and this indicates that the latter are not affected by an overlapping bias. On the other hand, equation (5) involves at each side an expected exchange rate (that is, $\tilde{s}_{3, t}$ on the left-hand-side and $\tilde{s}_{12, t}$ on the right-hand-side) and the spot rate, implying a possible simultaneity bias. To check this, we calculated the correlations between the residuals and each exogenous variable in the case of each currency. It turns out that these correlations are systematically insignificant at the $1 \%$ level, suggesting that there is no significant simultaneity bias. Lastly, regarding the test suggested by Johnson (1963), we found that there is no bias due to colinearities between exogenous variables.

${ }^{16}$ Ito (1994) provides econometrical support to this result in the case of the Yen/US dollar exchange rate.

17 This is in line with Chinn and Frankel (2002) who suggest using the PPP as a proxy measure of the target.

${ }^{18}$ Nevertheless, in the case of Ireland, we found that the 12-month ahead expected Punt/US Dollar exchange rate is significantly correlated with the spread of price indices.

19 The general expression of the extrapolative process is $\tilde{s}_{t, 3}-s_{t}=\alpha_{1}+\sum_{i=1}^{n} \gamma_{i}\left(s_{t-i+1}-s_{t-i}\right)+\varepsilon_{1 t}$. According to preliminary tests of equation (5), we can admit that $\mathrm{n}=3$ and $\gamma_{1}=\gamma_{2}=\gamma_{3}$, these conditions leading to equation (8).

20 The standard adaptive process is $\tilde{s}_{t, 3}-\widetilde{s}_{t-3,3}=\beta^{\prime}\left(s_{t}-\tilde{s}_{t-3,3}\right)$. The assumption of an early revision of expectations leads to the relation $\widetilde{s}_{t, 3}-\widetilde{s}_{t-1,3}=\beta\left(s_{t}-\tilde{s}_{t-1,3}\right)$, which is formally equivalent to (9) with $\alpha_{2}=0$ and $\varepsilon_{2 t}=0$.

21 The standard ECM is $\tilde{s}_{t, 3}-\tilde{s}_{t-1,3}=\mu_{1}\left(\bar{s}_{t-1}-\tilde{s}_{t-1,3}\right)+\mu_{2}\left(\bar{s}_{t}-\bar{s}_{t-1}\right)$. Rearranging terms so as to get the expected change in the exchange rate at the left hand side yields equation (10).

${ }^{22}$ The log-likelihood function has been optimized using an algorithm based on the routine VA13AD of the Harwell Subroutine Library, which minimizes a function knowing its first and second derivatives with respect to the parameters to be estimated. A technical description of the construction of the likelihood is available from the authors upon request.

${ }^{23}$ Following Hamilton (1994), we constrained the probabilities $\lambda_{k}$ to vary between 0 and 1 and to sum up to 1 by writing them as $\lambda_{k}=q_{k}^{2} /\left(1+\sum_{i=1}^{6} q_{i}^{2}\right)$ and $\lambda_{7}=1 /\left(1+\sum_{i=1}^{6} q_{i}^{2}\right)$, where $-\infty<q_{k}<+\infty, k=1, \ldots, 6$ and by estimating the unconstrained auxiliary parameters $q_{k}$. At the optimum, an additional estimation of the whole set of parameters with the $\lambda_{k}$ 's is performed in order to produce the standard errors and the Wald statistics of these probabilities.

${ }^{24}$ Note that the high significance of the structural parameters $\gamma, \mu_{1}, \mu_{2}$ and $\beta$ whereas the simple processes do never occur is due to the fact that these parameters are also included in the mixed processes.

25 In order to check for the robustness of these results to a different coverage of currencies, we estimated our switching-regression model with the FRF/USD, DEM/USD, ITL/USD and GBP/USD series of exchange rates only. The maximum likelihood estimates were found to be similar to those obtained for our basket of six currencies. This lends support to robustness. 
26 The conditional probability of a regime $k(k=1, . .7)$ at time $\mathrm{t}$ is given by $P_{k t}=\lambda_{k} \varphi_{k t} / \sum_{i=1}^{7} \lambda_{i} \varphi_{i t}$, where $\varphi_{k t}=\varphi\left(\tilde{s}_{t, 3}-s_{t} \mid \omega_{t}=k, x_{t} ; \theta\right)$ is the density function of $\tilde{s}_{t, 3}-s_{t}$ conditional on the process $k, x_{t}$ a vector of independent variables and $\theta$ a vector of hyperparameters. At the unconstrained maximum likelihood estimates of the parameters, $T^{-1} \sum_{t=1}^{T} P_{k t}=\lambda_{k}, \forall k$ (Hamilton, 1994).

27 Among the 223 shifts in regimes evidenced in the sample, two consecutive regimes have exhibited one or two common components in 222 cases.

${ }^{28}$ Only at 21 months over 85 (24.7\%), all the currencies are characterized by the same process, whatever this process. 